\title{
BMJ Open Comparison of the university hospital and county hospitals in western Sweden to identify potential weak links in the early chain of care for acute stroke: results of an observational study
}

\author{
Birgitta Wireklint Sundström, ${ }^{1}$ Johan Herlitz, ${ }^{1}$ Per Olof Hansson, ${ }^{2}$ Peter Brink ${ }^{3}$
}

To cite: Wireklint Sundström B, Herlitz J, Hansson PO, et al. Comparison of the university hospital and county hospitals in western Sweden to identify potential weak links in the early chain of care for acute stroke: results of an observational study. BMJ Open 2015;5:e008228. doi:10.1136/bmjopen-2015008228

- Prepublication history for this paper is available online. To view these files please visit the journal online (http://dx.doi.org/10.1136/ bmjopen-2015-008228).

Received 18 March 2015 Revised 25 June 2015 Accepted 29 July 2015

\section{CrossMark}

For numbered affiliations see end of article.

\section{Correspondence to}

Professor Birgitta Wireklint Sundström;

birgitta.wireklint.sundstrom@ hb.se

\section{ABSTRACT}

Objective: To identify weak links in the early chain of care for acute stroke.

Setting: 9 emergency hospitals in western Sweden, each with a stroke unit, and the emergency medical services (EMS).

Participants: All patients hospitalised with a first and a final diagnosis of stroke-between 15 December 2010 and 15 April 2011. The university hospital in the city of Gothenburg was compared with 6 county hospitals.

Primary and secondary measures: (1) The system delay, that is, median delay time from call to the EMS until diagnosis was designated as the primary end point. Secondary end points were: (2) the system delay time from call to the EMS until arrival in a hospital ward, (3) the use of the EMS, (4) priority at the dispatch centre and (5) suspicion of stroke by the EMS nurse.

Results: In all, 1376 acute patients with stroke (median age 79 years; $49 \%$ women) were included. The median system delay from call to the EMS until (1) diagnosis (CT scan) and (2) arrival in a hospital ward was $3 \mathrm{~h}$ and $52 \mathrm{~min}$ and $4 \mathrm{~h}$ and $22 \mathrm{~min}$, respectively. The system delay (1) was significantly shorter in county hospitals. (3) The study showed that $76 \%$ used the EMS (Gothenburg $71 \%$; the county $79 \%$; $\mathrm{p}<0.0001)$. (4) Priority 1 was given at the dispatch centre in $54 \%$ of cases. (5) Stroke was suspected in $65 \%$ of cases. A prenotification was sent in $32 \%$ (Gothenburg 52\%; the county 20\%; $p<0.0001$ ).

Conclusions: System delay is still long and only a small fraction of patients received thrombolysis. Three of four used the EMS (more frequent in the county). They were given the highest priority at the dispatch centre in half of the cases. Stroke was suspected in two-thirds of the cases, but a prenotification was seldom sent to the hospital.

\section{INTRODUCTION}

Stroke is the common name for cerebral infarctions, intracerebral haemorrhages and

\section{Strengths and limitations of this study}

- The major strength of this study is that all patients with stroke were included in the analyses, regardless of whether or not patients were admitted to a stroke unit.

- The complete period of time from symptom onset until diagnosis, arrival in a hospital ward and treatment with thrombolysis or thrombectomia was studied. This makes the study sample more representative and unique than those most often found in the literature.

- Patients treated in university hospitals were compared with those in county hospitals.

- The limitations are partly due to the observational retrospective design, which might have led to selection bias. We are therefore not able to draw any certain conclusions about cause and effect.

- A major limitation was that data were missing for many of the variables mainly due to poor documentation in the emergency medical services and medical records. Furthermore, a majority of the patients did not know the exact time of the onset of symptoms and could not therefore be included in the analyses.

subarachnoid haemorrhages. Approximately 17 million patients suffer from stroke each year in the whole world, and stroke causes almost 6 million deaths. ${ }^{1}{ }^{2}$ In addition, a large number of the survivors are left with mental and physical impairment and require assistance with the activities of daily living. Thus, stroke constitutes an enormous burden for the individuals affected and for society. ${ }^{1}{ }^{2}$ A variety of symptoms are described in stroke. The most known are the sudden onset with hemiparesis, hemihypesthesia, loss of vision, speech disturbances, loss of consciousness, nausea and compromised balance. ${ }^{3}$ Sometimes, the symptoms 
are more atypical and the onset of symptoms might be more gradual. ${ }^{4}$ The duration and degree of ischaemia determine the extent of damage ${ }^{5}{ }^{6}$ In the assessment of stroke, medical staffs have to rely on the patient's medical history, risk factors and clinical examination. Stroke is an acute condition that requires immediate treatment and the advent of thrombolytic therapy in acute stroke has resulted in improved prognosis. ${ }^{7}$ Improved outcome has also been reported for patients with stroke treated in stroke units, focusing on rehabilitation, early mobilisation, acute general care such as control of blood glucose and blood pressure. ${ }^{8} 9$ However, the number of patients eligible for thrombolysis is unsatisfyingly low, to a large extent due to the fact that patients arrive in hospital late after onset of symptoms. ${ }^{10}$ The delay until start of treatment can be divided into two major components: prehospital and in-hospital delay. The prehospital delay constitutes the largest proportion of delay time and is a major challenge, ${ }^{11}$ where the patient's decision time accounts for the largest part. ${ }^{8}$ Prehospital time encompasses symptom onset to hospital arrival.

Prehospital delay can be reduced by decreasing the patient decision time, increasing the utilisation of the emergency medical services (EMS) system, improving the early identification of stroke symptoms and finally increasing the utilisation of clinical trials. Prehospital clinical trials have been developed for patients in whom the EMS nurse suspects stroke, in order to gain fast access to thrombolysis and care at stroke units. The stroke triage pathway has been started to shorten door-to-needle time ${ }^{12} 13$ and to shorten dramatically the time from call to the EMS until arrival at a stroke unit. ${ }^{14}$ Studies have also shown that prenotification by personnel in the EMS is associated with shorter door-to-needle time $^{1516}$ and the increase of the use of thrombolysis in stroke. $^{9}$

The fact that all potential candidates for thrombolytic therapy must undergo a CT scan before treatment contributes to in-hospital delay. Availability and efficiency of in-hospital CT scanning is therefore crucial. ${ }^{9}$ However, for patients arriving early in hospital, inappropriate delay may occur prior to being seen by a physician and performing a CT scan; inefficient in-hospital management might preclude candidates for thrombolysis. ${ }^{17} \mathrm{By}$ increased knowledge about what causes delay in acute management of stroke and by evaluation of weak links, the number of patients eligible for thrombolytic treatment can be increased. Several studies have demonstrated delays in stroke care, ${ }^{3} 49111819$ but only a few have attempted to study the complete period of time including both prehospital and in-hospital delay. ${ }^{9}$ Prehospital delay has been shown to be strongly correlated to in-hospital delay. ${ }^{20}$ This study focuses on system delay, that is, delay time from call to the EMS until diagnosis (CT scan) and arrival in a hospital ward.

The aim of this study is to identify weak links in the early chain of care in acute stroke care. Primary and secondary measures: (1) the system delay, time from call to the EMS until diagnosis (CT scan), was designed as a primary end point. Secondary end points were: (2) the system delay time from call to the EMS until arrival in a hospital ward, (3) the use of the EMS, (4) priority at the dispatch centre and (5) suspicion of stroke by the EMS nurse. Patients treated in a university hospital were compared with those in six county hospitals.

\section{METHODS}

\section{Study design and setting}

The study has an observational retrospective design and was carried out in Region Västra Götaland in western Sweden. The region has approximately 1.6 million inhabitants and nine emergency hospitals with a stroke unit at each hospital. In the region, there are 84 ambulances, all staffed with one EMS nurse day and night all days of the week.

The participating hospitals were the Sahlgrenska University Hospital in the city of Gothenburg (which consists of three separate hospital units: Sahlgrenska, Östra and Mölndal, each with an emergency ward and a stroke unit), Södra Älvsborg Hospital (Borås), Norra Älvsborg Hospital (Trollhättan), Skaraborg Hospital (which consists of two separate hospital units: Skövde and Lidköping), Alingsås Hospital and Kungälv hospital. All the hospitals are linked to the EMS. This implies that the EMS nurse initiates direct contact with a stroke coordinator at the stroke unit. This system makes it possible for many patients to be transported either directly to a stroke unit or directly to a CT scan, thus bypassing the emergency department (ED). The study was conducted from 15 December 2010 to 15 April 2011.

\section{Inclusion and exclusion criteria}

Patients were included in the study if they were admitted to a hospital ward in Region Västra Götaland, and where the final diagnosis was stroke. The diagnoses included were: intracerebral haemorrhage, unspecific brain haemorrhage, cerebral infarction and stroke not classified as infarction or haemorrhage (International Classification of Diseases 10th Revision; ICD-10: I61.0-I64.9, with the exception of I62.0 and I62.1).

The exclusion criteria were patients with a final diagnosis of stroke in whom symptom onset took place after admission to hospital. Patients with subarachnoid haemorrhage (ICD-10: I60.0-I60.9) and extracranial haemorrhage (ICD-10: I62.0-I62.1) were not included in the analyses.

\section{Data collection}

Data were gathered from hospital and EMS records including the hospital diagnosis register. The data were divided into four phases: (1) symptom onset, (2) the dispatch centre, (3) the EMS transport or other transport if not the EMS and (4) first assessment at hospital. 
The EMS is using the Rapid Emergency Triage and Treatment System (RETTS). ${ }^{21}$ With the support of the RETTS, each patient is given an emergency symptoms and signs (ESS) number, based on symptoms and vital parameters (objective signs), and is assigned a triage colour that serves to indicate the priority.

\section{Statistical analyses}

All data were registered in a database designed for this project. All analyses were performed using the SAS software. Descriptive data are presented mainly as crude percentages. When comparing the university hospital with county hospitals, any eventual differences in proportions were evaluated with Fisher's exact test for dichotomous variables, and continuous variables were evaluated with the Wilcoxon two-samples test. All tests were two tailed. Owing to the large number of $p$ values calculated, a $p$ value of $<0.01$ was regarded as statistically significant.

\section{Ethical approval}

Written informed consent was obtained from all patients prior to any data collection.

\section{RESULTS}

\section{Baseline characteristics}

The total number of patients registered during the 4-month period was 1376 of whom 534 (39\%) were brought to units of the University Hospital in Gothenburg (able 1). Of all cases, 165 (12\%) had a final diagnosis of intracerebral haemorrhage (ICD-10:
I61.1-I61.9), seven cases (0.5\%) had a final diagnosis of unspecified haemorrhage (ICD-10: I62.9), 200 cases $(14.5 \%)$ had a final diagnosis of embolic infarction (ICD-10: I63.2 or I63.4), $359(26.1 \%)$ cases had a final diagnosis of non-embolic infarction (ICD-10: I63.0, I63.1, I63.3, I63.5-I63.8), 605 cases (44\%) had a final diagnosis of unspecified infarction (ICD-10: I63.9) and 40 cases $(2.9 \%)$ had a final diagnosis of unspecified stroke (ICD-10: I64.9) (not shown in the table).

The most frequent previous diseases were a history of hypertension, stroke and atrial fibrillation (table 1). There were no significant differences between patients treated at the university hospital compared with those in county hospitals. Results were further divided into three groups: all included patients, patients at the university hospital and patients at county hospitals in the region.

\section{Time to CT, hospital ward and treatment}

The median system delay from call to the EMS until diagnosis (CT scan) and arrival in a hospital ward was $3 \mathrm{~h}$ and $52 \mathrm{~min}$ and $4 \mathrm{~h} 22 \mathrm{~min}$, respectively (not shown in the table). System delay, from calling the EMS until diagnosis (CT scan), was significantly shorter in county hospitals (table 2). However, system delay from calling for EMS until arrival in a hospital ward tended to be shorter in university hospitals. When individual hospitals were evaluated, we found that in the university hospital the median delay from call for EMS until CT was performed varied from $4 \mathrm{~h}$ and $14 \mathrm{~min}$ to $7 \mathrm{~h}$ and $14 \mathrm{~min}$ in the three units. In the six county hospitals, the median delay varied from $2 \mathrm{~h}$ and $28 \mathrm{~min}$ to $7 \mathrm{~h}$ and $31 \mathrm{~min}$.

Table 1 Baseline characteristics of patients on admission to hospital

\begin{tabular}{|c|c|c|c|c|}
\hline & $\begin{array}{l}\text { All patients } \\
n=1376\end{array}$ & $\begin{array}{l}\text { University hospital } \\
n=534\end{array}$ & $\begin{array}{l}\text { County hospitals } \\
\mathrm{n}=842\end{array}$ & p Value* \\
\hline Age $(0) \dagger$ (years; mean, median) & 76,79 & 76,78 & 77,79 & 0.27 \\
\hline \multicolumn{5}{|l|}{ Sex $\%(0)$} \\
\hline Women & 49 & 50 & 51 & 0.82 \\
\hline \multicolumn{5}{|l|}{ Patients history (\%) } \\
\hline Diabetes $(0,1)$ & 19 & 18 & 20 & 0.48 \\
\hline Hypertension $(0,2)$ & 51 & 52 & 50 & 0.70 \\
\hline Atrial fibrillation $(0,3)$ & 24 & 24 & 24 & 0.95 \\
\hline Heart failure $(0,3)$ & 10 & 11 & 10 & 0.27 \\
\hline Myocardial infarction $(0,4)$ & 16 & 15 & 17 & 0.26 \\
\hline Angina pectoris $(0,4)$ & 7 & 6 & 7 & 0.38 \\
\hline Amaurosis fugax $(0,2)$ & 0.9 & 0.9 & 0.9 & 1.00 \\
\hline Transitory ischaemic attack $(0,2)$ & 8 & 8 & 8 & 0.68 \\
\hline Stroke $(0,1)$ & 26 & 27 & 26 & 0.57 \\
\hline Claudicatio intermittens $(0,2)$ & 2 & 2 & 2 & 0.86 \\
\hline Sleep apnoea syndrome $(0,4)$ & 2 & 2 & 1 & 0.52 \\
\hline Malignancy $(0,4)$ & 14 & 16 & 12 & 0.054 \\
\hline \multicolumn{5}{|l|}{ Living alone (\%) (3) } \\
\hline Yes & 50 & 49 & 49 & 0.50 \\
\hline \multicolumn{5}{|l|}{ Need for interpreter $(\%)(0,1)$} \\
\hline Yes & 3 & 5 & 3 & 0.046 \\
\hline
\end{tabular}


Table 2 Time to CT, hospital, ward and treatment

\begin{tabular}{|c|c|c|c|}
\hline & $\begin{array}{l}\text { University hospital } \\
\mathrm{n}=534\end{array}$ & $\begin{array}{l}\text { County hospital } \\
\mathrm{n}=842\end{array}$ & p Value* \\
\hline \multicolumn{4}{|l|}{ Radiological evaluation (CT) } \\
\hline From call to EMS $(\mathrm{N}=227, \mathrm{~N}=508) \dagger$ & & & 0.006 \\
\hline Range & $29 \min -6$ days 7 h 2 min & 32 min-6 days 22 h 5 min & \\
\hline Median, IQ range & 4 h 55 min; 2 h 31 min-9 h 8 min & 3 h 27 min; 1 h 59 min-7 h 7 min & \\
\hline From arrival in hospital $(\mathrm{N}=483, \mathrm{~N}=625)$ & & & 0.005 \\
\hline Range & $1 \mathrm{~min}-6$ days 6 h $15 \mathrm{~min}$ & $3 \mathrm{~min}-6$ days $20 \mathrm{~h} 10 \mathrm{~min}$ & \\
\hline Median, IQ range & 3 h 35 min; 1 h 42 min-6 h 42 min & 2 h 38 min; 1 h 11 min-6 h 22 min & \\
\hline \multicolumn{4}{|l|}{ Arrival in ward } \\
\hline From call to EMS $(\mathrm{N}=211, \mathrm{~N}=629)$ & & & 0.011 \\
\hline Range & $3 \mathrm{~min}-21 \mathrm{~h} 8 \mathrm{~min}$ & $35 \mathrm{~min}-17 \mathrm{~h} 38 \mathrm{~min}$ & \\
\hline Median, IQ range & 3 h 49 min; 2 h 4 min-6 h 13 min & 4 h 26 min; 3 h 2 min-6 h 33 min & \\
\hline From arrival in hospital $(\mathrm{N}=486, \mathrm{~N}=801)$ & & 0.0007 & \\
\hline Range & $0 \mathrm{~min}-23 \mathrm{~h} 45 \mathrm{~min}$ & 0 min-22 h 52 min & \\
\hline Median, IQ range & 2 h 46 min; 1 h 12 min-4 h 57 min & 3 h 22 min; 1 h 40 min-5 h 31 min & \\
\hline \multicolumn{4}{|l|}{ Thrombolysis or thrombectomia } \\
\hline From call to EMS (N=19, $\mathrm{N}=29)$ & & & 0.64 \\
\hline Range & $52 \min -15$ h $58 \min$ & $61 \mathrm{~min}-3 \mathrm{~h} 36 \mathrm{~min}$ & \\
\hline Median, IQ range & 1 h 40 min; 1 h 4 min-2 h 49 min & 1 h 43 min; 1 h 30 min-2 h 7 min & \\
\hline From arrival in hospital $(\mathrm{N}=25, \mathrm{~N}=30)$ & & & 0.53 \\
\hline Range & $0 \mathrm{~min}-2 \mathrm{~h} 36 \mathrm{~min}$ & $11 \mathrm{~min}-2 \mathrm{~h} 47 \mathrm{~min}$ & \\
\hline Median, IQ range & $45 \mathrm{~min} ; 19 \mathrm{~min}-1 \mathrm{~h} 17 \mathrm{~min}$ & $44 \mathrm{~min} ; 34 \mathrm{~min}-1 \mathrm{~h} 13 \mathrm{~min}$ & \\
\hline
\end{tabular}

The shortest delay was seen in the smallest of all nine hospitals (Alingsås; 100 beds). The number of beds in each hospital varied between 100 and 800 .

The overall median times from arrival in the hospital until CT scan and arrival in a hospital ward were $3 \mathrm{~h}$ $0 \mathrm{~min}$ and $3 \mathrm{~h} 11 \mathrm{~min}$, respectively. The in-hospital delay, from arrival in the hospital until a CT scan, was shorter in county hospitals. The median time from arrival in hospital until thrombolysis or thrombectomia was $45 \mathrm{~min}$, with no differences between groups.

Of all the patients, $70 \%$ were directly referred to a stroke unit and $11 \%$ were never admitted to a stroke unit (table 3). This was more frequent in university hospitals. Only $7 \%$ of all patients were treated with either thrombolytic agents or underwent thrombectomy or carotid endarterectomy.

\section{Circumstances at onset of symptoms}

Of all the patients, $76 \%$ used the EMS (more frequent in county hospitals; table 4). One of four patients woke up with their symptoms (more frequent in the university hospital). The proportion of patients who arrived in hospital within $4 \mathrm{~h}$ after onset of symptoms was $67 \%$, but

Table 3 Type of medical ward, radiological evaluation and revascularisation

\begin{tabular}{|c|c|c|c|c|}
\hline & $\begin{array}{l}\text { All patients } \\
n=1376\end{array}$ & $\begin{array}{l}\text { University hospital } \\
n=534\end{array}$ & $\begin{array}{l}\text { County hospitals } \\
n=842\end{array}$ & p Value* \\
\hline \multicolumn{5}{|l|}{ Type of medical ward $(0,1) \dagger \%$} \\
\hline Stroke unit directly & 70 & 77 & 65 & $<0.0001$ \\
\hline Initially other ward but later referred to a stroke unit & 19 & 16 & 22 & 0.014 \\
\hline Other ward & 11 & 6 & 13 & $<0.0001$ \\
\hline \multicolumn{5}{|l|}{ Radiological evaluation $(0,2) \%$} \\
\hline $\mathrm{CT}$ & 99 & 99 & 99 & 1.00 \\
\hline MR & 11 & 14 & 10 & 0.014 \\
\hline \multicolumn{5}{|l|}{ Revascularisation } \\
\hline Thrombolysis $(130,1)$ & 5 & 5 & 4 & 0.33 \\
\hline Thrombectomy $(140,1)$ & 0.7 & 0.8 & 0.6 & 0.73 \\
\hline Carotid endarterectomy $(140,5)$ & 1 & 1 & 1 & 0.78 \\
\hline
\end{tabular}


Table 4 Circumstances at onset of symptoms

\begin{tabular}{|c|c|c|c|c|}
\hline & $\begin{array}{l}\text { All patients } \\
n=1376\end{array}$ & $\begin{array}{l}\text { University hospital } \\
n=534\end{array}$ & $\begin{array}{l}\text { County hospitals } \\
\mathrm{n}=842\end{array}$ & p Value* \\
\hline \multicolumn{5}{|c|}{ Wake up with symptoms $(\%)(35,32) \dagger$} \\
\hline Yes & 25 & 31 & 21 & 0.002 \\
\hline \multicolumn{5}{|c|}{ Place of symptom onset $(\%)(8,11)$} \\
\hline Indoors & 96 & 96 & 96 & 1.00 \\
\hline \multicolumn{5}{|c|}{ If indoors $(\%)(0,5)$} \\
\hline At home & 94 & 93 & 95 & 0.10 \\
\hline \multicolumn{5}{|c|}{ Mode of transport $(\%)(1,0,4)$} \\
\hline \multicolumn{5}{|c|}{ EMS system } \\
\hline Yes & 76 & 71 & 79 & $<0.0001$ \\
\hline \multicolumn{5}{|c|}{ If yes, detour via primary care $(0,4)$} \\
\hline Yes & 7 & 6 & 7 & 0.51 \\
\hline
\end{tabular}

information was only available in a minority of patients (not shown in the table).

\section{Prehospital assessment by the dispatch centre and EMS nurse}

Only $54 \%$ of patients were given the highest priority by the dispatch centre (table 5). This figure was reduced to $34 \%$ when the patients were assessed by the EMS nurse (higher priority in county hospitals). However, the EMS nurse suspected a stroke in $65 \%$ of cases. Assessment by the EMS nurse showed that the most common symptoms were paralysis and speech disturbances (facial droop was more common in the county hospital group). The degree of consciousness was Reaction Level Scale $1^{22}$ in $78 \%$. Almost all patients had oxygen saturation over $90 \%$. The diastolic blood pressure was over $90 \mathrm{~mm} \mathrm{Hg}$ in $46 \%$ and $12 \%$ had a heart rate above $100 \mathrm{bpm}$.

Prenotifications by EMS nurses to the hospital were made in $32 \%$ of patients using EMS transport; that is, the nurse contacted a stroke coordinator/neurologist (52\% in the university hospital vs $20 \%$ in county hospitals; $\mathrm{p}<0.0001)$.

\section{First assessment at hospital}

The first physician who examined the patient at the hospital (in the ED or ward) suspected a stroke in $82 \%$ of cases (more frequent in university hospitals). Stroke signs and warning symptoms such as hemiparesis, hemihypesthesia and syncope were more frequent in university hospitals. Elevation of diastolic blood pressure was more frequent in county hospitals (table 6).

\section{DISCUSSION}

This study shows that the need exists to improve the early chain of care for patients with stroke in western Sweden in order to decrease the system delay time until diagnosis (CT scan). The delay times are shown to be very high (almost $4 \mathrm{~h}$, on average). This result is nevertheless in agreement with a previous study from the same area where the median time from emergency call to the ward was almost $5 \mathrm{~h}^{12}$

Although some patients are rapidly transported to the appropriate level of care, the early chain of care in subsets of patients with stroke probably needs to be improved. A system where stroke diagnoses are set by the EMS nurse and the patient is transported directly to the CT scan and thereafter directly to the stroke unit instead of the ED may shorten this delay. Bypassing the ED can decrease the delay time to treatment for the patient and reduce the number of patients admitted to the ED. This stroke triage pathway was unfortunately not fully utilised in the participating EMS systems and was not fully developed in all participating hospitals at the time of the present study.

That as many as $76 \%$ of the patients with stroke in this study used EMS transport is a higher proportion than was previously reported. Studies from France and the USA showed that the percentage of patients with stroke transported by the EMS was lower, only about 35$65 \% .^{1823}{ }^{24}$ Still, in this study, one of four patients with stroke did not use the EMS. Since studies have shown that EMS transport is related to a shorter time to hospital admission and shorter in-hospital delay prior to the right treatment, ${ }^{19}{ }^{25-28}$ it is not acceptable that onefourth should receive delayed treatment. Thus, in terms of EMS transport in cases of stroke, there is still room for improvement. The cause might be unspecific symptoms with a gradual onset, not motivating the patient to call the emergency dispatch centre. Studies have shown that factors such as a gradual onset of symptoms, no motor dysfunction, unspecific and mild symptoms are less often recognised as representing stroke. ${ }^{19}$ Non-recognition of the warning signs of stroke increases the delay time before calling the dispatch centre and seeking medical care. ${ }^{27} 29$ Only $39 \%$ of the patients in this study were certain about the time for symptom onset. 
Table 5 Prehospital assessment (\%) by dispatch centre and EMS nurse

\begin{tabular}{|c|c|c|c|c|}
\hline & $\begin{array}{l}\text { All patients } \\
\mathrm{n}=1028\end{array}$ & $\begin{array}{l}\text { University hospital } \\
\mathrm{n}=368\end{array}$ & $\begin{array}{l}\text { County hospitals } \\
n=660\end{array}$ & p Value \\
\hline Priority at dispatch centre $(35,0)$ & & & & 0.94 \\
\hline 1 & 54 & 54 & 54 & \\
\hline 2 & 41 & 41 & 42 & \\
\hline 3 & 5 & 5 & 4 & \\
\hline 4 & 0.3 & 0.4 & 0.3 & \\
\hline Priority by EMS nurse $(0,5)$ & & & & 0.0006 \\
\hline 1 & 34 & 28 & 36 & \\
\hline 2 & 51 & 50 & 51 & \\
\hline 3 & 15 & 21 & 12 & \\
\hline 4 & & & & \\
\hline \multicolumn{5}{|l|}{ Suspicion of stroke by EMS nurse $(2,1)^{\star}$} \\
\hline Yes & 65 & 61 & 68 & 0.054 \\
\hline RETTS triage $(4,4)$ & & & & 0.06 \\
\hline Red & 27 & 26 & 28 & \\
\hline Orange & 25 & 22 & 26 & \\
\hline Yellow & 41 & 44 & 40 & \\
\hline Green & 7 & 8 & 6 & \\
\hline \multicolumn{5}{|l|}{ Symptoms (\%) } \\
\hline Arm weakness $(12,7)$ & 47 & 46 & 47 & 0.63 \\
\hline Leg weakness $(12,7)$ & 42 & 43 & 42 & 0.78 \\
\hline Facial drop $(16,10)$ & 28 & 20 & 32 & $<0.001$ \\
\hline Numbness $(21,16)$ & 12 & 9 & 14 & 0.046 \\
\hline Speech disturbances $(15,9)$ & 44 & 40 & 47 & 0.24 \\
\hline Consciousness (RLS) $(15,9)$ & & & & 0.25 \\
\hline 1 & 78 & 75 & 79 & \\
\hline 2 & 12 & 13 & 11 & \\
\hline 3 & 5 & 4 & 5 & \\
\hline \multirow[t]{2}{*}{$\geq 4$} & 6 & 7 & 5 & \\
\hline & $\begin{array}{l}\text { All patients } \\
n=1028\end{array}$ & $\begin{array}{l}\text { University hospital } \\
\mathrm{n}=368\end{array}$ & $\begin{array}{l}\text { County hospitals } \\
n=660\end{array}$ & P† \\
\hline \multicolumn{5}{|l|}{ Capillary oxygen saturation $(4,6)^{*}$} \\
\hline$<90 \%$ & 6 & 4 & 8 & 0.020 \\
\hline Systolic blood pressure $(\mathrm{mm} \mathrm{Hg})(7,9)$ & & & & 0.25 \\
\hline$<100$ & 1 & 0.6 & 2 & 0.10 \\
\hline$>140$ & 73 & 69 & 74 & 0.07 \\
\hline$>200$ & 11 & 12 & 11 & 0.83 \\
\hline Diastolic blood pressure $(\mathrm{mm} \mathrm{Hg})(7,9)$ & & & & 0.25 \\
\hline$>90$ & 46 & 40 & 48 & 0.02 \\
\hline$>120$ & 6 & 7 & 6 & 0.57 \\
\hline \multicolumn{5}{|l|}{ Heart rate $(\mathrm{bpm})(3,4)$} \\
\hline$<50$ & 1 & 1 & 1 & 0.77 \\
\hline$>100$ & 12 & 11 & 13 & 0.61 \\
\hline
\end{tabular}

To increase the awareness of stroke signs and warning signals, educational campaigns are needed. In the USA, a study in Missoula showed that a high-intensity public education campaign can increase community awareness of the warning signs for stroke and the need to call the dispatch centre. ${ }^{30}$ In Texas, a similar campaign increased the number of patients with stroke treated with thrombolysis. ${ }^{31}$ Another study in Korea showed that stroke awareness on the part of patients, as well as of bystanders, had a great impact on arrival time at hospital. $^{32}$ A national campaign to increase awareness of stroke symptoms was started in Sweden in 2011, after this study was carried out. This campaign may have reduced prehospital delay and increased the number of patients transported to hospital by the EMS.

The next weak link is the priority given at the dispatch centre, which in this study showed that only $54 \%$ were given priority 1 . In a subset of patients where 
Table 6 First assessment at hospital

\begin{tabular}{|c|c|c|c|c|}
\hline & $\begin{array}{l}\text { All patients } \\
n=1376\end{array}$ & $\begin{array}{l}\text { University hospital } \\
\mathrm{n}=534\end{array}$ & $\begin{array}{l}\text { County hospitals } \\
n=842\end{array}$ & p Value \\
\hline \multicolumn{5}{|l|}{ Suspicion of stroke $(0,6,1) \dagger$} \\
\hline Yes & 82 & 87 & 80 & 0.001 \\
\hline Consciousness (according to RLS) $(8,5)$ & & & 0.47 & \\
\hline 1 & 78 & 77 & 78 & \\
\hline 2 & 10 & 8 & 11 & \\
\hline \multirow[t]{2}{*}{3} & 4 & 3 & 4 & \\
\hline & $\geq 4$ & 5 & 6 & 5 \\
\hline Uncertain & 3 & 6 & 2 & \\
\hline \multicolumn{5}{|l|}{ Symptoms (\%) } \\
\hline Hemiparesis/plegia $(8,4)$ & 55 & 58 & 50 & 0.006 \\
\hline Facial droop $(10,5)$ & 33 & 36 & 31 & 0.09 \\
\hline Numbness, hemihypesthesia $(4,11)$ & 21 & 25 & 16 & $<0.0001$ \\
\hline Double vision $(17,12)$ & 3 & 2 & 4 & 0.11 \\
\hline Aphasia/dysphasia $(11,7)$ & 40 & 39 & 41 & 0.68 \\
\hline Headache $(15,14)$ & 15 & 16 & 14 & 0.35 \\
\hline Vertigo $(15,15)$ & 23 & 25 & 20 & 0.08 \\
\hline Syncope $(13,14)$ & 4 & 6 & 2 & $<0.0001$ \\
\hline Compromised balance $(17,14)$ & 21 & 22 & 20 & 0.26 \\
\hline Dysphagia $(20,17)$ & 5 & 5 & 6 & 0.79 \\
\hline \multicolumn{5}{|l|}{ Oxygen saturation $(5,22)$} \\
\hline \multirow[t]{2}{*}{$<90$} & 4 & 3 & 5 & 0.06 \\
\hline & $\begin{array}{l}\text { All patients } \\
n=1376\end{array}$ & $\begin{array}{l}\text { University hospital } \\
\mathrm{n}=534\end{array}$ & $\begin{array}{l}\text { County hospitals } \\
n=842\end{array}$ & p Value \\
\hline \multicolumn{5}{|l|}{ Blood pressure $(\mathrm{mm} \mathrm{Hg})$} \\
\hline \multicolumn{5}{|l|}{ Systolic $(1,12)$} \\
\hline$<100$ & 5 & 5 & 5 & 0.69 \\
\hline$>140$ & 74 & 71 & 77 & 0.02 \\
\hline$>200$ & 3 & 3 & 4 & 0.42 \\
\hline \multicolumn{5}{|l|}{ Diastolic $(3,12)$} \\
\hline$>90$ & 40 & 33 & 44 & $<0.0001$ \\
\hline$>120$ & 4 & 3 & 4 & 0.46 \\
\hline \multicolumn{5}{|l|}{ Heart rate $(\mathrm{bpm})(3,15)$} \\
\hline$<50$ & 2 & 2 & 2 & 1.00 \\
\hline$>100$ & 9 & 9 & 9 & 0.92 \\
\hline \multicolumn{5}{|l|}{ Heart rhythm $(7,18)$} \\
\hline Sinus rhythm & 74 & 74 & 74 & 0.89 \\
\hline Atrial fibrillation & 22 & 21 & 22 & 0.48 \\
\hline Other rhythm & 4 & 5 & 4 & 0.73 \\
\hline
\end{tabular}

information was available, we found that $67 \%$ of patients arrived in hospital within $4 \mathrm{~h}$ of symptom onset. Previous studies from other countries have shown longer delay times. ${ }^{25} 33$ Of all the patients with stroke including $12 \%$ with a cerebral haemorrhage, only $7 \%$ were potentially revascularised with medication or surgery. Previous studies have found that the major reason for the low rate of early thrombolysis is the late admission to hospital. $^{25} 34$ The time frame for thrombolysis is set at $4.5 \mathrm{~h}$, which means that the patient needs to get to the hospital at least within $4 \mathrm{~h}$ after symptom onset. A randomised study has reported that a higher prioritisation of stroke at the dispatch centre increases the use of thrombolysis and reduces the time to the stroke unit. ${ }^{35}$ The findings of this study therefore underline the fact that the management of acute stroke can and must be improved at the dispatch centre, through being given the highest priority and through stroke protocols with high compliance. ${ }^{36}$

The EMS nurse suspected a stroke in $65 \%$ of all cases compared to $82 \%$ for the first examining physician at the hospital. There is a difference of $17 \%$ between the EMS nurses and the physicians' ability to detect stroke on the scene. A pilot study from Sweden, where the EMS nurses had special training to diagnose stroke symptoms, showed that a prehospital diagnosis of stroke 
led to a relatively high diagnostic accuracy of stroke. ${ }^{12}$ It also resulted in decreased delay to treatment at a stroke unit, also shown in other studies. ${ }^{12-14}$ Improved prehospital triage is also shown with a specialised stroke ambulance staffed with a specialised stroke team. ${ }^{37}$ As new treatments for acute stroke are discovered, the EMS and prehospital personnel are assuming increasingly important roles in the assessment and treatment of acute ischaemic stroke. ${ }^{38}$ However, they must be appropriately trained and working within a well-established and wellcoordinated healthcare system for stroke management. ${ }^{39}$ A study from the USA investigated how to increase more inexperienced physicians' ability to diagnose patients with stroke. They found that increased knowledge about key features that distinguish stroke from other facial symptoms made the physicians better at identifying stroke diagnoses. ${ }^{17}$ Earlier studies suggest offering individualised feedback on each separate case to all healthcare professionals on a monthly or quarterly basis, ${ }^{40}$ as a method of keeping them up to date concerning the results of their care input. ${ }^{41}$ The overall aim is to optimise stroke care and management and to improve implementation times and outcomes.

The EMS nurse sent a prenotification to the hospital by contacting a physician or a stroke coordinator in only $32 \%$ of the cases. Of these patients, some were referred to the ED and not to a stroke unit. This means that they only used the stroke pathway for about half of all the patients in whom they suspected a stroke. Thus, $11 \%$ of the patients were not treated at a stroke unit. It is well known that stroke units are the most efficient and evidence-based wards for managing patients with stroke. ${ }^{81542}$ Therefore, it is not reasonable that 1 of 10 patients with stroke does not reach a stroke unit at all during their hospital stay. Further investigation is needed to discover the reasons for this. These results are significant since one of the major aims of this study was to identify the weak links. According to these results, there is need for improvement in using the EMS nurses' opportunity to contact a stroke coordinator/neurologist each time a stroke is suspected.

The medical history of patients with stroke indicated, as one might suspect, a group of patients with atherosclerotic disease. About half of the patients had a history of hypertension prior to the event. It is possible that this figure might be even larger if the cases discovered during hospital treatment for stroke were included, since many patients probably had undiscovered hypertension. The social circumstances showed that most patients had symptom onset in their home. This may be related to the time period of the study, being during the winter months. According to this study, almost half of the patients lived alone, which is an important finding since previous studies have shown that living alone is associated with longer delay time to treatment. ${ }^{19}$ One study from Australia found that only $3 \%$ of all patients called the emergency dispatch centre themselves; the rest were dependent on a relative or friend. ${ }^{43}$
Comparison between the university hospital and county hospitals

An interesting observation was that system delay, that is, time from calling the EMS until diagnosis (CT scan), was significantly shorter in county hospitals. However, system delay to arrival in a hospital ward tended to be shorter in the university hospital. Nevertheless, the median time from arrival in hospital until thrombolysis or thrombectomia showed no differences between groups. The most important difference between the two groups was that the use of the EMS was more frequent in county hospitals, probably a beneficial factor. However, the university hospital group showed a greater frequency of suspicion of stroke by the ED physicians.

The shorter delay to arrival in a hospital ward in the university hospital may be explained by a higher rate of prenotification by the EMS nurse resulting in more direct admissions to a hospital ward.

\section{Further improvements of the acute care of stroke}

There are a number of possibilities to shorten the system delay in the EMS system. With the use of telemedicine, a physician at a distant hospital might assess the patient via videophone and thereby improve the early diagnostic procedure. ${ }^{44}{ }^{45}$ The use of brain imaging prior to hospital admission has already been started in Germany with a specialised ambulance vehicle ${ }^{46}$ and in Norway with air ambulances. ${ }^{47}$ The time from onset of symptoms to thrombolytic treatment can be reduced to $<90 \mathrm{~min}$ with the aid of an ambulance equipped with a CT scanner. ${ }^{48}$ Finally, a microwave system in order to eliminate cerebral bleeding has shown promising results in the hospital setting ${ }^{49}$ and will soon be evaluated also in the prehospital setting in Sweden.

There is most likely a huge variability in terms of system delay in the early handling of stroke when seen in a global perspective. We know that in some regions $\mathrm{CT}$ is performed in the $\mathrm{ED},{ }^{50}$ whereas in some developing countries this type of investigation is not even available.

\section{Strengths and limitations of the study}

The major strength in this study is that all patients with stroke were included in the analyses, regardless of whether or not patients were admitted to a stroke unit. Furthermore, there are few previous studies that have studied the complete period of time from symptom onset until diagnosis. This makes the study sample more representative and unique than those most often found in the literature. That patients treated in university hospitals were compared with those in county hospitals should also be considered as a strength of the study.

The limitations are partly due to the observational retrospective design, which might have led to selection bias. We are therefore not able to draw any certain conclusions about cause and effect. A major limitation was that data were missing for many of the variables mainly 
due to poor documentation in the EMS and medical records. With regard to the primary end point, we compared patients with and without information on the time between call for EMS and CT scan on a number of background variables including age, sex, patients history and priority given by EMS. No significant differences were found, suggesting that a representative population was evaluated. A majority of the patients did not know the exact time for the onset of symptoms and could therefore not be included in the analyses. The limited data that are presented on this variable should therefore be interpreted with caution.

\section{CONCLUSIONS}

For further improvement of the early care of stroke, the system delay time should be reduced even more. In western Sweden, only half of the patients were given the highest priority at the dispatch centre. Three of four patients were transported by the EMS and in two-thirds of these cases the EMS nurse suspected stroke, but they seldom sent a prenotification to the stroke unit. By improved training in identifying and assessing patients with stroke, EMS nurses will be able to contact the stroke unit and use the stroke pathway system even better. The study showed that patients often arrived in the hospital within the time window for thrombolytic therapy, but that most of these patients were still not treated with thrombolytics. The reason for this in-hospital delay is not clear and further studies are required.

\section{Author affiliations \\ ${ }^{1}$ Faculty of Caring Science, Work Life and Social Welfare, Research Centre PreHospen, University of Borås, The Prehospital Research Centre of Western Sweden, Borås, Sweden \\ ${ }^{2}$ Department of Molecular and Clinical Medicine/Cardiology, Sahlgrenska Academy, Institute of Medicine, University of Gothenburg, Gothenburg, Sweden \\ ${ }^{3}$ Emergency Medical Service System, NU-Hospital Organisation, Trollhättan, Sweden}

Acknowledgements The authors would like to thank Helle Wijk, University of Gothenburg, for support in design of the data protocol and the application form to the Research Ethics Committee; Jonny Lindqvist, Sahlgrenska University Hospital, for statistical analyses and hosting the data. They also thank the data collecting group staffed with Sylvia Kalju, Emelie Larsson, Sofie Nordkvist and Andreas Wändahl from the EMS in Region Västra Götaland, who retrospectively collected data from medical records.

Contributors BWS, JH, POH and PB were involved in study conception and design, analysis and interpretation of findings, and finally the development of the manuscript. PB organised and carried out the data collection together with the data collecting group. BWS and JH were responsible for manuscript preparation and final approval of the manuscript.

Funding This work was supported by The Health and Medical Care Committee of the Regional Executive Board, Region Västra Götaland, Sweden.

Competing interests None declared.

Patient consent Obtained.

Ethics approval The design of the study was approved by the Research Ethics Committee in Gothenburg (registration number 514-10).
Provenance and peer review Not commissioned; externally peer reviewed.

Data sharing statement No additional data are available.

Open Access This is an Open Access article distributed in accordance with the Creative Commons Attribution Non Commercial (CC BY-NC 4.0) license, which permits others to distribute, remix, adapt, build upon this work noncommercially, and license their derivative works on different terms, provided the original work is properly cited and the use is non-commercial. See: http:// creativecommons.org/licenses/by-nc/4.0/

\section{REFERENCES}

1. Bennett DA, Krishnamurthi RV, Barker-Collo S, et al., Global Burden of Diseases, Injuries, and Risk Factors 2010 Study Stroke Expert Group. The global burden of ischemic stroke: findings of the GBD 2010 study. Glob Heart 2014:9:107-12.

2. Krishnamurthi RV, Moran AE, Forouzanfar $\mathrm{MH}$, et al., Global Burden of Diseases, Injuries, and Risk Factors 2010 Study Stroke Expert Group. The global burden of hemorrhagic stroke: a summary of findings from the GBD 2010 study. Glob Heart 2014;9:101-6.

3. Palomeras E, Fossas $\mathrm{P}$, Quintana M, et al. Emergency perception and other variables associated with extra-hospital delay in stroke patients in the Maresme region (Spain). Eur $J$ Neurol 2008;15:329-35.

4. Gargano JW, Wehner S, Reeves MJ. Do presenting symptoms explain sex differences in emergency department delays among patients with acute stroke? Stroke 2009;40:1114-20.

5. Donnan GA, Fisher M, Macleod M, et al. Stroke. Lancet 2008;371:1612-23.

6. Lakhan SE, Kirchgessner A, Hofer M. Inflammatory mechanisms in ischemic stroke: therapeutic approaches. J Translat Med 2009;7:97.

7. Lee KR, Bluhmki E, von Kummer R, et al. Time to treatment with intravenous alteplase and outcome in stroke: an updated pooled analysis of ECASS, ATLANTIS, NINDS and EPITHET trials. Lancet 2010;375:1695-703.

8. Díez-Tejedor E, Fuentes B. Acute care in stroke: the most importance of early intervention to achieve better brain protection. Cerebrovasc Dis 2004;17:130-7.

9. Evenson KR, Foraker RE, Morris DL, et al. A comprehensive review of prehospital and in-hospital delay times in acute stroke care. Int $J$ Stroke 2009;4:187-99.

10. Barber PA, Zhang J, Demchuk AM, et al. Why are stroke patients excluded from TPA therapy? An analysis of patient eligibility. Neurology 2001;56:1015-20.

11. Chang KC, Tseng MC, Tan TY. Prehospital delay after acute stroke in Kaosiung, Taiwan. Stroke 2004;35:700-4.

12. Wennman I, Klittermark P, Herlitz J, et al. The clinical consequences of a prehospital diagnosis of stroke by emergency medical service system. A pilot study. Scand J Trauma Resus Emerg Med 2012;20:48.

13. Kim SK, Lee SY, Bae HU, et al. Prehospital notification reduced the door-to-needle time for iv t-PA in acute ischemic stroke. Eur $J$ Neurology 2009;16:1331-5.

14. Desai JA, Smith EE. Prenotification and other factors involved in rapid tPA administration. Curr Atheroscler Rep 2013;15:337.

15. Mehdiratta M, Woolfenden AR, Chapman KM, et al. Reduction in IV t-PA door to needle times using an Acute Stroke Triage Pathway. Can J Neurol Sci 2006;33:214-16.

16. Lau AY, Soo YO, Graham CA, et al. An expedited stroke triage pathway: the key to shortening the door-to-needle time in delivery of thrombolysis. Hong Kong Med J 2010;16:455-62.

17. Hand J, Kwan J, Lindley RI, et al. Distinguishing between stroke and mimic at the bedside: the brain attack study. Stroke 2006;37:769-75.

18. Lacy CR, Suh DC, Bueno M, et al. Delay in presentation and evaluation for acute stroke: Stroke Time Registry for Outcome Knowledge and Epidemiology (STROKE). Stroke 2001;32:63-9.

19. Wester $\mathrm{P}, \mathrm{Rådberg} \mathrm{J}$, Lundgren $\mathrm{B}$, et al. Factors associated with delayed admission to hospital and in-hospital delays in acute stroke and TIA: a prospective, multicenter study. Seek-Medical-Attentionin-Time Study Group. Stroke 1999;30:40-8.

20. Faiz KW, Sundseth A, Thommessen B, et al. Reasons for low thrombolysis rate in a Norwegian ischemic stroke population. Neurol Sci 2014;35:1977-82.

21. Widgren BR, Jourak M. Medical Emergency Triage and Treatment System (METTS): a new protocol in primary triage and secondary priority decision in emergency medicine. J Emerg Med 2011;40:623-8.

22. Starmark JE, Stålhammar D, Holmgren E. The Reaction Level Scale (RLS 85). Acta Neurochir (Wien) 1988;91:12-20. 
23. Derex L, Adeleine $\mathrm{P}$, Nighoghossian N, et al. Factors influencing early admission in a French Stroke unit. Stroke 2002;33:153-9.

24. Kleindorfer DO, Lindsell CJ, Broderick JP, et al. Community socioeconomic status and prehospital times in acute stroke and transient ischemic attack: do poorer patients has longer delays from 911 call to the emergency department. Stroke 2006;37:1354-5.

25. Harraf F, Sharma AK, Brown MM, et al. A multicentre observational study of presentational study of presentation and early assessment of acute stroke. Brit Med J 2002;325:17-21.

26. Barr J, McKinley S, O'Brien E, et al. Patient recognition of and response to symtoms of TIA or stroke. Neuroepidemiology 2006;26:168-75.

27. Meretoja A, Strbian D, Mustanoja S, et al. Reducing in-hospital delay to 20 minutes in stroke thrombolysis. Neurology 2012;79:306-13.

28. Millin MG, Gullett T, Daya MR. EMS management of acute strokeout-of-hospital treatment and stroke system development (resource document to NAEMSP position statement). Prehosp Emerg Care 2007;11:318-25.

29. Yasuyuki I, Kuniyasu W, Kensaku S, et al. First impression at stroke onset plays an important role in early hospital arrival. Intern Med 2006;45:447-51.

30. Fogle CC, Oser CS, Troutman TP, et al. Public education strategies to increase awareness of stroke warning signs and the need to call 911. J Public Health Manag Pract 2008;14:e17-22.

31. Morgenstern LB, Bartholomew LK, Grotta JC, et al. Substained benefit of a community and professional intervention to reduce prehospital delays in patients with cerebrovascular events. Arch Intern Med 2009;169:1484-90.

32. Kim YS, Park SS, Bae HJ, et al. Stroke awareness decreases prehospital delay after acute ischemic stroke in Korea. BMC Neurol 2011;11:2.

33. Keaskin Ö, Kalemoglu M, Ulusoy RE. A clinical investigation into prehospital and emergency department delays in acute stroke care. Med Princ Pract 2005;14:408-12.

34. Herlitz J, Wireklintsundström B, Bång A, et al. Early identification and delay to treatment in myocardial infarction and stroke: differences and similarities. Scand J Trauma, Resusc Emerg Med 2010;18:48.

35. Berglund A, Svensson L, Sjöstrand C, et al., ASTA Collaborators. Higher prehospital priority level of stroke improves thrombolysis frequency and time to stroke unit: the Hyper Acute STroke Alarm (HASTA) study. Stroke 2012;43:2666-70.

36. Ramanujam P, Guluma KZ, Castillo EM, et al. Accuracy of stroke recognition by emergency medical dispatchers and paramedicsSan Diego experience. Prehosp Emerg Care 2008;12:307-13.
37. Wendt M, Ebinger M, Kunz A, et al., STEMO Consortium. Improved prehospital triage of patients with stroke in a specialized stroke ambulance: results of the pre-hospital acute neurological therapy and optimization of medical care in stroke study. Stroke 2015;46:740-5.

38. Rajajee V, Saver J. Prehospital care of the acute stroke patient. Tech Vasc Interv Radiol 2005;8:74-80.

39. Crocco TJ. Streamlining stroke care: from symptom onset to emergency department. J Emerg Med 2007;33:255-60.

40. van Dishoeck AM, Dippel DW, Dirks M, et al. Measuring Quality Improvement in Acute Ischemic Stroke Care: Interrupted Time Series Analysis of Door-to-Needle Time. Cerebrovasc Dis Extra 2014;4:149-55.

41. Sheppard JP, Mellor RM, Bailey SM, et al., BBC CLAHRC Investigators. Protocol for an observation and implementation study investigating optimisation of the management of stroke and transient ischaemic attack (TIA). BMJ Open 2012;2:e001430.

42. Leonardi-Bee J, Bath PM, Phillips SJ, et al., IST Collaborative group. Blood pressure and clinical outcomes in the International Stroke Trial. Stroke 2002;33:1315-20.

43. Mosley I, Nicol M, Donnan G, et al. Stroke symptoms and the decision to call for an ambulance. Stroke 2007;38:61-366.

44. Demaerschalk BM, Vegunta S, Vargas BB, et al. Reliability of real-time video smartphone for assessing National Institutes of Health Stroke Scale scores in acute stroke patients. Stroke 2012;43:3271-7.

45. Gonzalez MA, Hanna N, Rodrigo ME, et al. Reliability of prehospital real-time cellular video phone in assessing the simplified National Institutes of Health Stroke Scale in patients with acute stroke: a novel telemedicine technology. Stroke 2011;42:1522-7.

46. Ebinger M, Winter B, Wendt $M$, et al., STEMO Consortium. Effect of the use of ambulance-based thrombolysis on time to thrombolysis in acute ischemic stroke: a randomized clinical trial. JAMA 2014;311:1622-31

47. Lossius HM, Lund CG. Pre-hospital treatment of stroke-time is brain. Tidsskr Nor Legeforen 2012;132:1848-9.

48. Walter S, Kostopoulos P, Haass A, et al. Diagnosis and treatment of patients with stroke in a mobile stroke unit versus in hospital: a randomised controlled trial. Lancet Neurol 2012;11:397-404.

49. Persson M, Fhager A, Trefne HD, et al. Microwave-based stroke diagnosis making global prehospital thrombolytic treatment possible. IEEE Trans Biomed Eng 2014;61:2800-17.

50. Handschu R, Littmann R, Reulbach U, et al. Telemedicine in emergency evaluation of acute stroke: interrater agreement in remote video examination with a novel multimedia system. Stroke 2003;34:2842-6. 